\title{
Article \\ Closing Force Evaluation of a Sample Return Capsule for a Phobos Sample Return Mission
}

\author{
Radu Mihalache*(D), Dragos Mihai, Gheorghe Megherelu, Ionut Florian Popa (D), Ionut Sebastian Vintila $\mathbb{D}$ \\ and Alexandru Paraschiv \\ Romanian Research and Development Institute for Gas Turbines COMOTI, 061126 Bucharest, Romania; \\ dragos.mihai@comoti.ro (D.M.); gheorghe.megherelu@comoti.ro (G.M.); ionut.popa@comoti.ro (I.F.P.); \\ sebastian.vintila@comoti.ro (I.S.V.); alexandru.paraschiv@comoti.ro (A.P.) \\ * Correspondence: radu.mihalache@comoti.ro
}

Citation: Mihalache, R.; Mihai, D.;

Megherelu, G.; Popa, I.F.; Vintila, I.S.;

Paraschiv, A. Closing Force

Evaluation of a Sample Return Capsule for a Phobos Sample Return Mission. Appl. Sci. 2021, 11, 8115. https://doi.org/10.3390/ app11178115

Academic Editor: Marwan Al-Haik

Received: 9 July 2021

Accepted: 25 August 2021

Published: 31 August 2021

Publisher's Note: MDPI stays neutral with regard to jurisdictional claims in published maps and institutional affiliations.

Copyright: (c) 2021 by the authors. Licensee MDPI, Basel, Switzerland. This article is an open access article distributed under the terms and conditions of the Creative Commons Attribution (CC BY) license (https:/ / creativecommons.org/licenses/by/ $4.0 /)$.

\begin{abstract}
The mission objective of the Phobos Sample Return is to collect and return $100 \mathrm{~g}$ of Phobos' surface material to Earth inside a tight enclosure composed of a Vault, a Sample Container and sealing elements. One important aspect of the project was the development of a closing mechanism capable of ensuring a pushing force high enough compared to the available force of the robotic arm $(40 \mathrm{~N})$. The need for a higher pushing force derived from the design tests which were carried out to experimentally determine the necessary force to overcome the resistance of the sealing element when the vault is closed. Two types of sealing elements, custom made for this project, along with two SC with different geometrical shapes in the sealing area were tested. For better accuracy, the tests considered the imposed operational temperature domain for the vault, ECSS standards and the test rig set-up being performed at environmental temperature $\left(+20^{\circ} \mathrm{C}\right),-20^{\circ} \mathrm{C},-60{ }^{\circ} \mathrm{C}$ and $+70{ }^{\circ} \mathrm{C}$. The results of the tests highlighted that the negative temperature has a significant influence over the closing force, as this force is increasing once the operational temperature is decreasing. Based on the work performed, the most suitable type of sealing element was identified, in particular the piston geometry which allows a smaller force to close the vault.
\end{abstract}

Keywords: Phobos; Sample Return Mission; sealing element; closing force; design test

\section{Introduction}

The Phobos Sample Return Mission is an incipient phase of the Mars Robotic Exploration and Preparation 2 (MREP-2) programme [1]. Due to the impact ejecta phenomenon described in [2], the regolith from Phobos may contain up to $250 \mathrm{ppm}$ in a concentration of particles coming from Mars' Surface. As the robotic exploration of Phobos is easier and safer than Mars, this makes it the perfect candidate to understand the origins of the red planet.

Throughout history, there have been several attempts to explore the Martian moon Phobos, in the frame of the Phobos 1 and 2 missions organized by the former Union of Soviet Socialist Republics (URSS) [3] and the Phobos-Grunt mission launched by Russia in 2011 [4]. While Phobos 1 failed prematurely, Phobos 2 managed to observe Phobos, Deimos and Mars before suffering a fault that led to losing contact with the operation centre [5]. Phobos-Grunt mission also encountered a failure in the early stages due to a programming error, which caused it to lose contact with the operation centre while it was on the Low Earth Orbit, later being destroyed as it descended uncontrolled in the Earth's atmosphere [4]. The European Space Agency (ESA) conducted a thorough study regarding a Phobos Sample Return Mission [6], highlighting the main challenges of this type of mission and proposing a possible mission architecture that would involve also Russia, considering their previous experience with the Martian moon. However, the Phobos Sample Return Mission was put on hold, as now the main goal of the space industry is to bring samples directly from Mars in the frame of the Mars 2020 mission currently 
ongoing [7]. Although the scientific community is focused right now on Mars' exploration, Japan Aerospace Exploration Agency (JAXA) prepares the Martian Moons Exploration (MMX) having among its purposes to establish the origin of Mars' natural satellites, as well as to bring to Earth regolith samples from Phobos' surface [8]. Currently, the mission is scheduled for launch in 2024 [9].

National Aeronautics and Space Administration (NASA) is currently studying Mars under the Mars Exploration Program, providing information related to planet evolution, history of geological and climate processes that have shaped Mars through time and the potential to have hosted life (its biological potential) [10]. A joint NASA-ESA mission is under development as part of NASA's Mars Exploration Program to bring samples of Martian rocks and soil back to Earth. The Sample Return Mission is designed to continue the work of NASA's Mars 2020 Rover. During the mission architecture, NASA is working on a Sample Retrieval Lander that would launch the retrieved samples into Mars orbit while ESA is working on an Earth Return Orbiter that would rendezvous with the samples in Mars orbit and bring them back to Earth. The foreseen launch date for the joint program is in 2026 and to touch Mars soil in 2028 [11].

Sample Return Missions are an extremely valuable resource, both for the scientific community and society. The analysis of samples from other bodies in the Solar System can answer fundamental questions for humankind, as well as give an insight regarding their resources (ores, rocks, etc.) which could prove useful in the future. The idea of Sample Return Missions dates back to 1969 [12], starting with the first steps made on the Moon. A year later, the former URSS performed the first sampling using remotecontrolled equipment [3], thus paving the way for future robotic exploration missions on other planetary bodies. A chronology of the Sample Return Missions is shown in Figure 1.

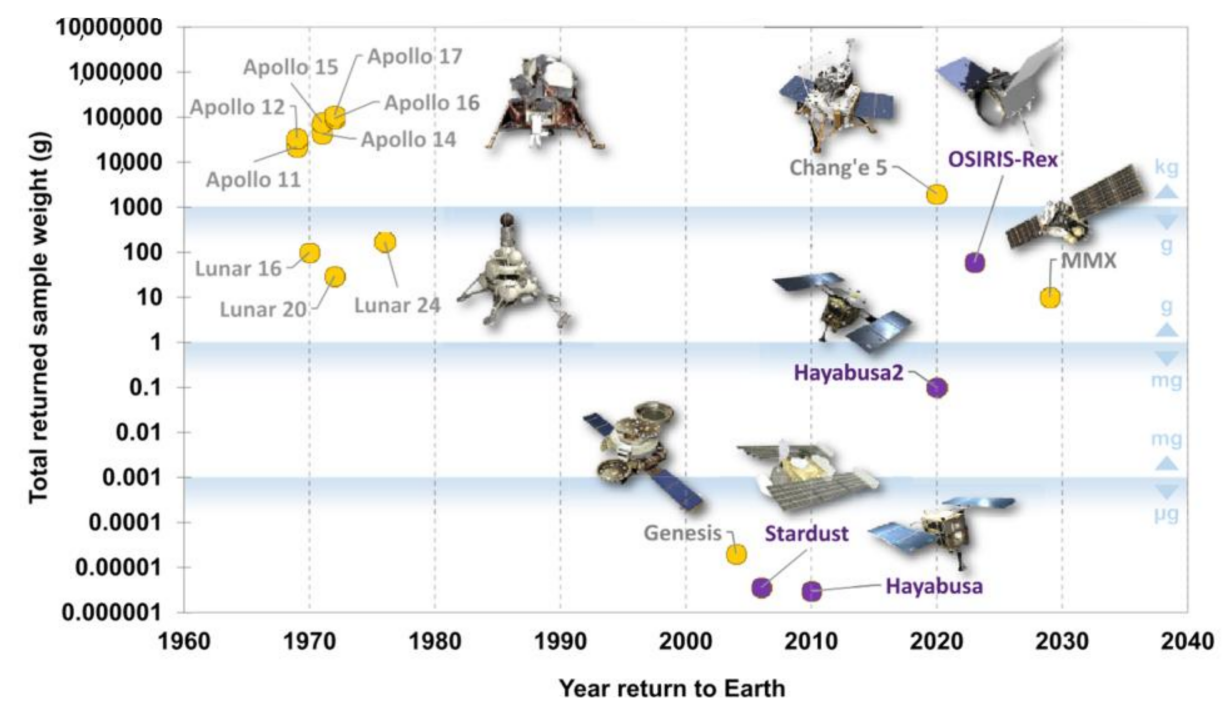

Figure 1. Sample Return Missions chronology in history [13] (image credit: NASA, JAXA, CNSA).

In recent history, the Sample Return Missions that stand out as being successful are the two Hayabusa missions conducted by JAXA [3], first to the Itokawa asteroid, and the second one to Ryugu, both celestial bodies being classified as NEO and potentially hazardous asteroids $[14,15]$. A third Sample Return Mission is on its way to Earth, NASA's OSIRIS-REx mission to Bennu [16].

In the first Hayabusa mission, the sample containment system was featured with two Viton O-rings, which were replaced in the second mission with a metallic seal due to the fluorocarbon material of the sealing elements which can interact with organic molecules (either terrestrial or from the sample) [17]. Although the Hayabusa concept (Figure 2a,b) uses the same actuation means as in the case of the concept developed in this paper, it shall be stated that the seal proposed by JAXA requires a pretension force because the sealing 
elements are mounted axially. Moreover, the Hayabusa concept is based on a touch-and-go mission architecture, while the proposed sealing and closing system are designed for a sampling-by-landing mission.

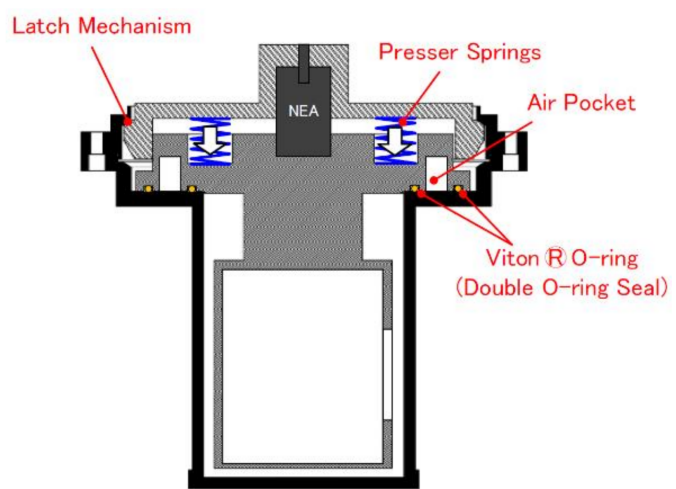

(a)

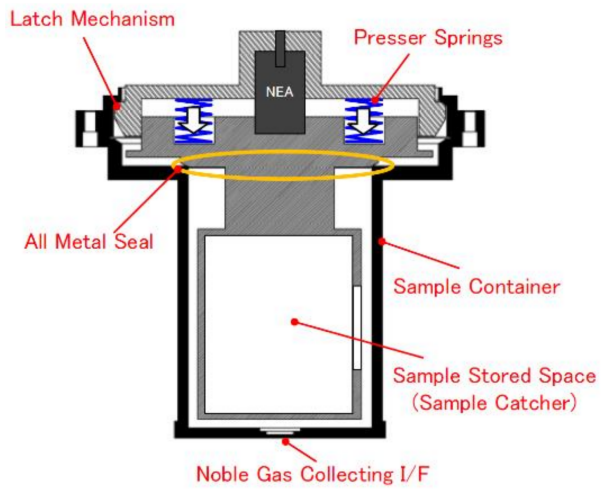

(b)

Figure 2. Sample Container concepts developed for the Hayabusa missions: (a) Hayabusa 1, foreseen with two Viton O-rings, (b) Hayabusa 2, foreseen with a metallic gasket [18].

The closing force evaluation is one of the key aspects of the mission proposed under the MREP-2 programme. The current architecture presumes using a robotic arm with limited capacities in terms of force (maximum $40 \mathrm{~N}$ of pushing force), having a sampling tool at the end which is used to collect the regolith in a Sample Container (SC), as seen in Figure 3a. After the regolith sampling, the vault is closed with the SC by pushing it with the necessary force using a closing mechanism, illustrated in Figure $3 b$.

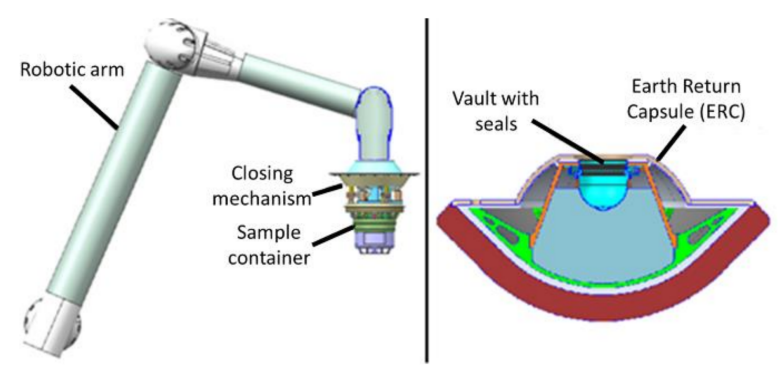

(a)

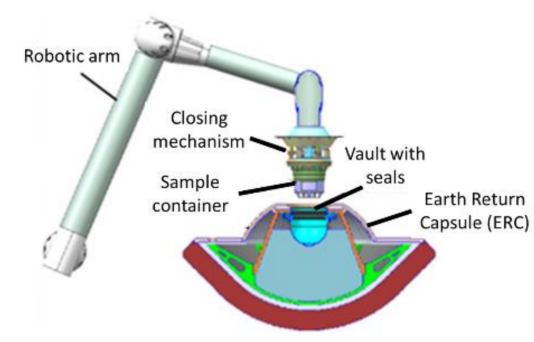

(b)

Figure 3. Sample return configuration: (a) after regolith sampling in the SC; (b) prior to performing the closing operation (images courtesy: Airbus Defence and Space UK).

Considering the requirements for a Phobos Sample Return Mission, a special closing mechanism with mechanical actuators was designed under a project coordinated by ESA. The actuators are helical compression springs, and their characteristics and specifications were established based on the experimental data and motorization factors given by the ECSS-E-ST-33-01C standard [19]. The closing mechanism, presented in Figure 4, is physically separated from the SC after the closing operation, remaining on Phobos along with the Robotic Arm). 


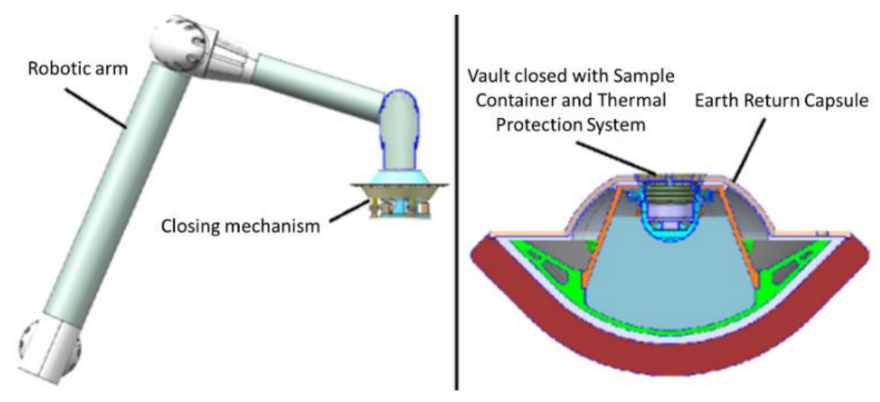

Figure 4. Sample return configuration after the closing operation (image courtesy: Airbus Defence and Space UK).

A set of requirements were used as input data for the development of the sealing and closing system. Several ones were considered as driving requirements when it comes to evaluating the necessary closing force to achieve the sealing and closing of the sample container vault, such as the ones presented in Table 1. It is to be noted that, during the mission, the vault shall withstand operational and non-operational temperatures, however, the vault closing operations are performed when the vault is in the range of the defined operational temperature. Consequently, to determine the required closing force through tests, the operational temperature domain was considered, altogether with $+/-5{ }^{\circ} \mathrm{C}$ margins according to ECSS-E-ST-33-01C.

Table 1. Driving requirements considered for the development of the closing and sealing system.

\begin{tabular}{cc}
\hline Req. No. & Description \\
\hline 1 & $\begin{array}{r}\text { The sample container vault shall be sealed using a maximum force of } 40 \mathrm{~N} . \\
\text { A redundant and fail-safe containment sealing system shall be envisaged for the vault. } \\
\text { The vault shall withstand a shock load of } 2000 \mathrm{~g} \text { for } 10 \mathrm{~ms} \text { without failure (leak tightness of the } \\
\text { vault correlated with the SR1 requirement-no particle or droplet of a fluid }>1 \mu \mathrm{m} \text { shall escape } \\
\text { or enter the sample canister, to be evaluated before and after the test). }\end{array}$ \\
& $\begin{array}{l}\text { The vault shall withstand the thermal environment encountered during the lifetime of the } \\
\text { mission (operating temperatures and non-operating temperatures): }\end{array}$ \\
& $\begin{array}{l}\text { Operational: }-40{ }^{\circ} \mathrm{C} /+80^{\circ} \mathrm{C} ; \\
\text { Non-Operational: }-10{ }^{\circ} \mathrm{C} /+90^{\circ} \mathrm{C} ;\end{array}$ \\
& $\begin{array}{r}\text { The sealing technologies to be considered shall be at the minimum: O-ring (including } \\
\text { composite gaskets with metallic spring energizer), metallic gasket and knife edge. }\end{array}$
\end{tabular}

The critical review of the technical requirements imposed by ESA consists in identifying their effects over the design, with respect to the optimal dimensioning of the components and the entire system. The first step was to determine the most suitable sealing technologies for this mission. This was achieved by performing a comprehensive trade-off analysis [20] which considered a large number of factors and aspects relevant to the mission. The results of this trade-off concluded that the best sealing technology is the use of radial seals with a composite jacket and metallic spring energizer. To achieve redundancy, the vault design featured two sealing elements with different diameters.

\section{Sample Containment and Closing System-Design Overview}

The vault is a metallic component that is placed inside an Earth Return Capsule (ERC, Figure 5). Its outside geometrical shape is a consequence of the ERC interior space geometry defined by Airbus Defence and Space UK and also, specified by one of the requirements. On the outside surface, the Vault has a flange with several holes used to fix the Vault on the ERC internal structure. There are several circular grooves on the Vault's inside. Two of these grooves are featured to mount the sealing elements and are closed type grooves. It is worth mentioning that these types of grooves were chosen due to the reasons of shape simplicity and reduced mass of the vault while accepting a more difficult mounting of the sealing elements, as well as their irreversible damage when removing them from the 
grooves. The other ones are foreseen to collect the regolith particles attached to the exterior surface of the SC to minimize the risk of deteriorating these surfaces when introducing the SC in the Vault. As a safety measure, all the grooves edges are also rounded to ease the passive alignment of the SC during the closing operation.

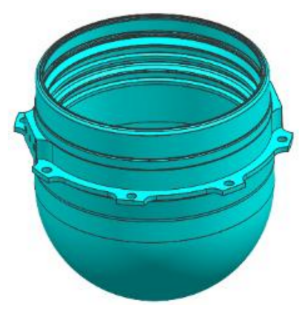

(a)

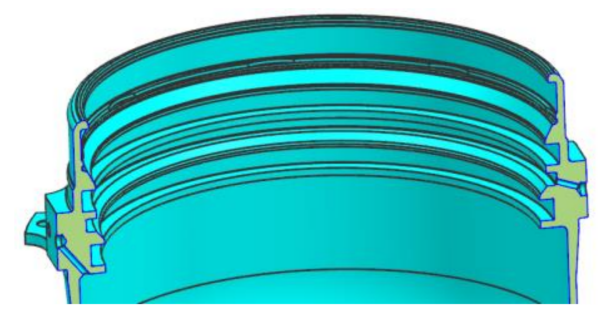

(b)

Figure 5. Vault design: (a) isometric view, (b) section through the leakage ports.

The Vault is sealed using the SC consisting of two mechanical subassemblies with different functional roles that were designed by, COMOTI and AIRBUS. COMOTI designed the upper part, highlighted with light green in Figure 6 which assures the vault sealing. Airbus designed the lower part highlighted with grey in Figure 6, which accommodates the sampled regolith.

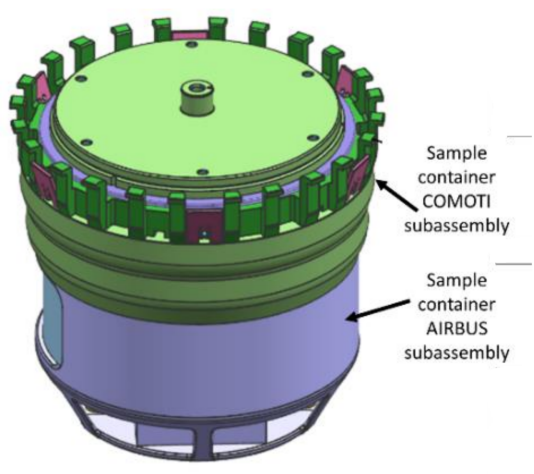

(a)

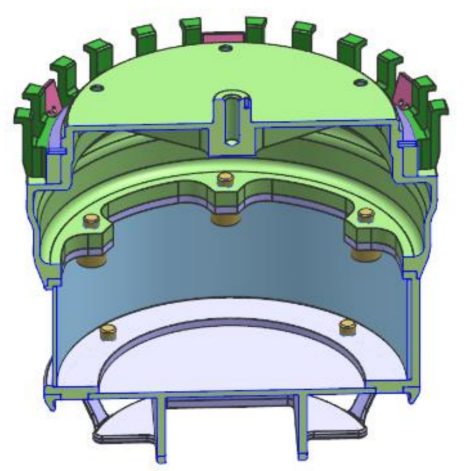

(b)

Figure 6. Sample Container: (a) isometric view, (b) section view.

The sealing surfaces of the Sample Container are featured with conical, rounded and cylindrical surfaces, without any sharp edges. Their purpose is to allow the initial interference between the surfaces and energization of the sealing elements [21] while inserting the SC inside the Vault and sealing the inner space of the Vault. These design particularities were the results of the closing force evaluation and they will be pursued in the following paragraphs of the paper. The Vault and the SC are closed using a dedicated mechanism called a Closing Mechanism, shown in Figure 7. This device has two main subassemblies, a special coupling, designed to overcome the robotic arm misalignments (not included in the current paper) and a Mechanical Press (MP) which ensures the closing operation. The MP uses the force provided by the helical springs which are maintained in compression state and, by whose relaxation during the closing operation, the SC is pushed inside the Vault, thus achieving the tightness. 


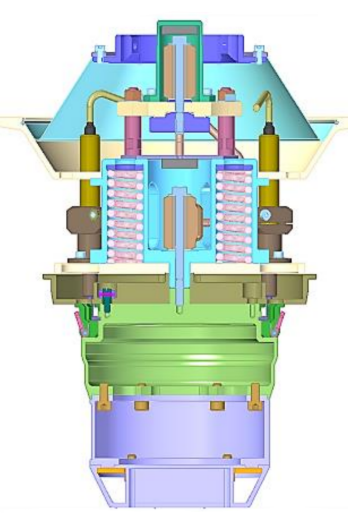

(a)

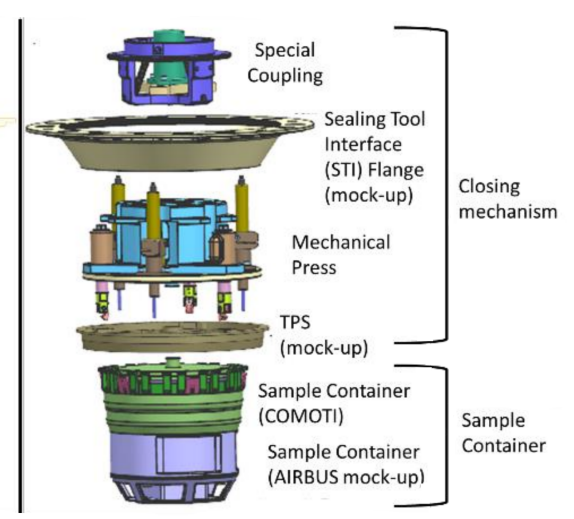

(b)

Figure 7. Closing Mechanism equipped with SC: (a) section, (b) exploded view.

Following a trade-off made during the first phase of the project and presented in [20], several sealing technologies were investigated and it was concluded that O-rings, gaskets, knife-edge and brazing (excluded in the end) could be reliable for the mission.

The three sealing technologies mentioned before were investigated once again in terms of the necessary force needed to achieve the tightness. The results indicated that the most suitable type of sealing element is radial sealing with a composite jacket and metallic spring energizer. As it was previously mentioned, the two sealing elements are placed on different diameters, as is depicted in Figure 8. The image shows also the specific areas of the $\mathrm{SC}$ which get in contact with the sealing elements during the closing operation.

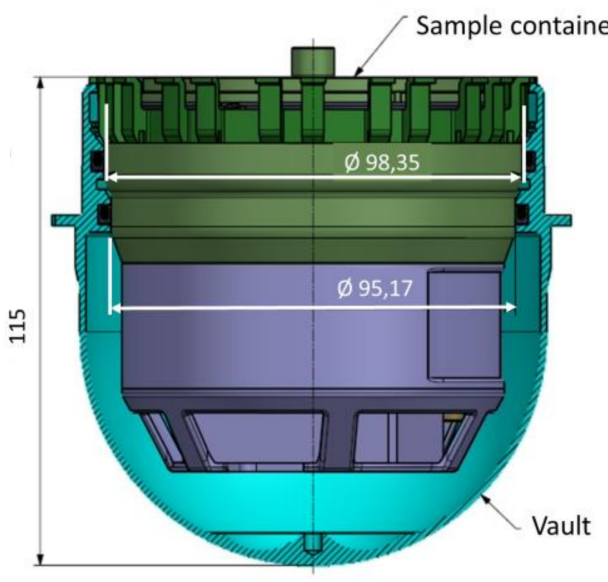

(a)

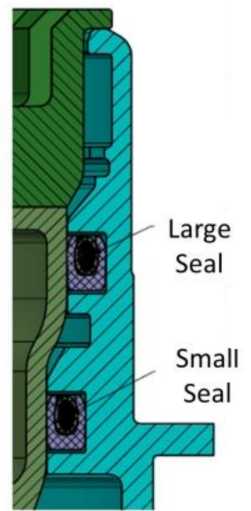

(b)

Figure 8. Vault closed with the SC: (a) section, (b) detail in the sealing area.

It shall be noted that the sealing elements described in this paper are custom made items designed and manufactured according to several requirements imposed by COMOTI. The two types of sealing elements are presented in Table 2 and, from now on, they will be referred to as Type I (supplied from Trelleborg) and Type II (supplied from Saint-Gobain) seals. Both types of sealing elements are designed for radial sealing located in closed grooves-rod type. 
Table 2. Sealing elements main characteristics.

Seal Type
Type I

\section{Design and Manufacturing of the Testing Devices}

To define the optimal design, to characterize the engineering parameters and to gather data, a device representative of the vault and SC was designed and manufactured for this test. This partial breadboard (dummy) was used to measure the closing force and, after that, the results of the tests were used to optimize the design. The testing device is presented in Figure 9.

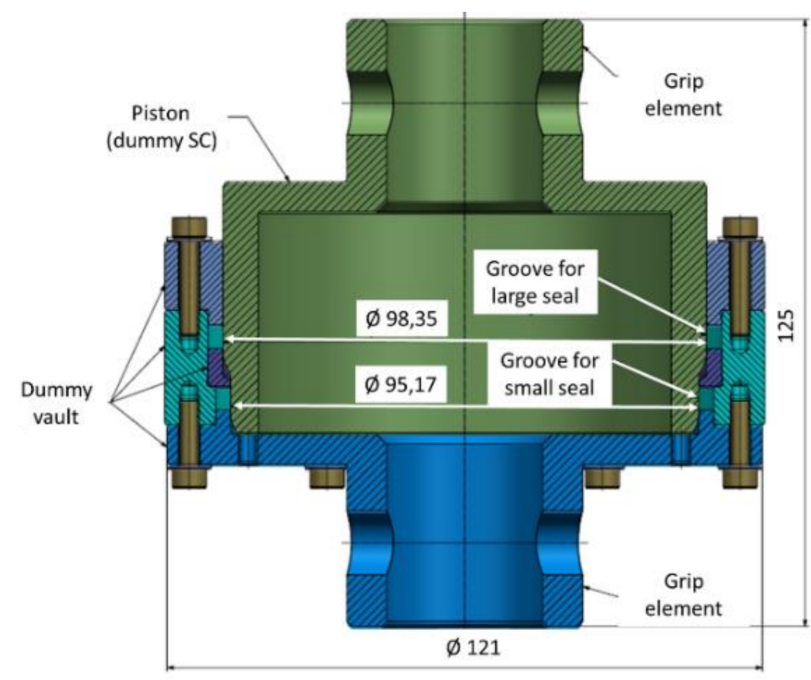

Figure 9. Cross-section through the testing device.

As it was previously mentioned, the Vault (Figure 5) was designed with closed grooves, however, to prevent the destruction of the sealing elements during the dismounting operation, the vault dummy was designed and manufactured with open grooves. The closing of the Vault is made by pushing the SC. The two sealing elements oppose by creating a resistant force during the Vault's closing when they get in contact with the SC surfaces. At the end of the stroke, the seals are in contact with the cylindrical surfaces of the SC. Due to the axial symmetry of the Vault and SC, the opposing force is radial. The closing stroke of the Vault is approximately $8 \mathrm{~mm}$. 
The pushing force exerted on the SC has two components:

- Forces necessary to enlarge the jackets and springs of the sealing elements;

- Forces to overcome the friction between the SC and sealing elements jackets on the entire length of the closing stroke.

Two partial breadboards (dummies) for the SC were designed, manufactured and used to measure the closing force. The difference between them is represented by different geometrical shapes in the areas that ensure the enlargement of the sealing elements, namely conical (CO) and toroidal shape (TO). The difference is depicted in Figure 10a,b and the manufactured parts (grade 5 Titanium alloy) are presented in Figure 10c. Hereinafter, the vault dummy will be called cylinder and the SC dummy will be called piston.

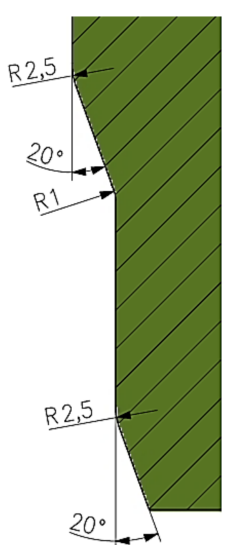

(a)

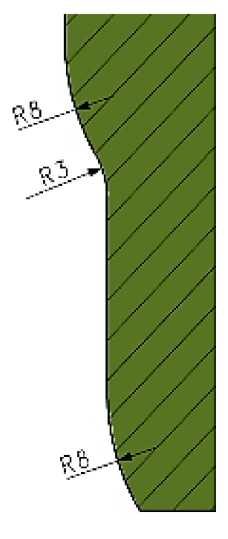

(b)

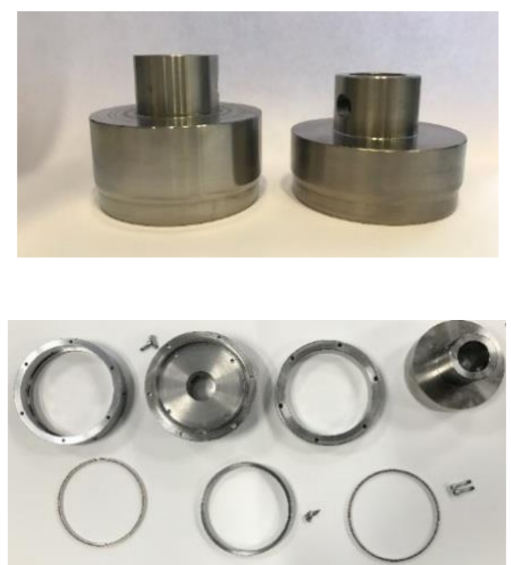

(c)

Figure 10. Sample Container detail in the sealing areas: (a) conical shape, (b) toroidal shape (c) manufactured components.

The surface finish is an important feature when it comes to ensuring the Vault's tightness. The sealing elements manufacturers recommended a roughness average (Ra) between $0.2 \mu \mathrm{m}$ and $0.4 \mu \mathrm{m}$. Following the finishing process, the corresponding values have been obtained, making the test more suggestive. The roughness evaluation was performed with a MahrSurf PS 10 device (Mahr GmbH, Gottingen, Germany), over a distance of $10 \mathrm{~mm}$ with a $1 \mathrm{~mm} / \mathrm{s}$ rate.

The sealing elements mounted in the cylinder have smaller inside diameters than those of the piston to achieve the necessary tightening for sealing when the piston is mounted in the cylinder. The evaluation of the necessary closing force was made for a stroke of $8 \mathrm{~mm}$, corresponding to the insertion path of the Sample Container in the Vault during the closing operation, illustrated in Figure 11.

When introducing the piston inside the cylinder (simulating the vault closing operation), the following phases take place:

- In the start position the piston does not touch the sealing elements;

- When moving the piston, it touches the sealing elements with the conical and rounded areas (Figure 12);

- When moving the piston up to $6 \mathrm{~mm}$, the opposing forces are those needed to enlarge the sealing elements and the friction forces that occurred on the sealing elements;

- After moving the piston, the sealing elements do not enlarge anymore and, until the end of the stroke, the forces opposing the movement of the piston are only the friction forces on the sealing elements. 


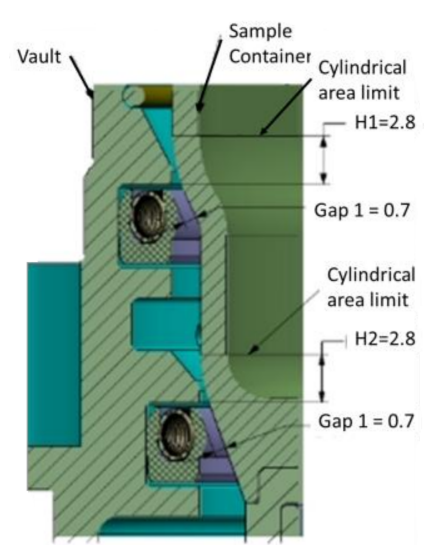

(a)

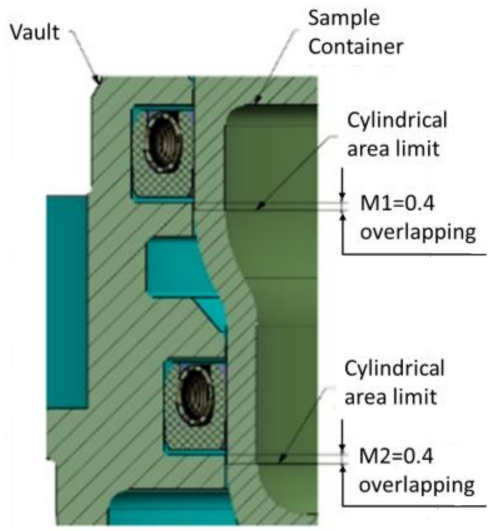

(b)

Figure 11. Sample Container nominal positions during the Vault closing operations: (a) SC in the start position of the closing operation, (b) SC at the end of the closing operation (Vault closed and sealed).

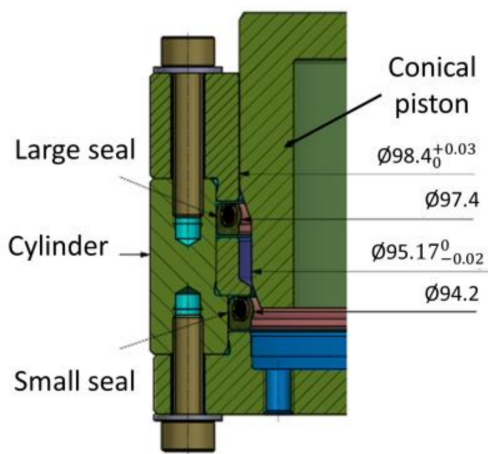

(a)

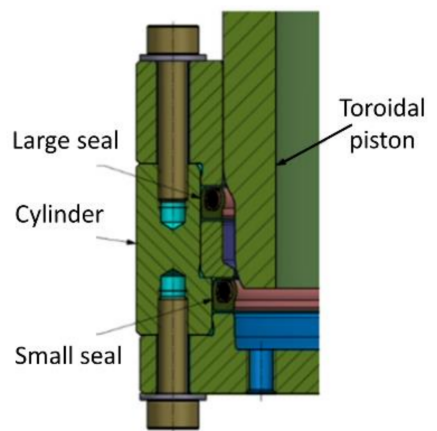

(b)

Figure 12. The device with seals mounted; (a) the starting position of the old piston in the cylinder; (b) the starting position of the new piston in the cylinder.

It shall be mentioned that both the old and the new piston come first in contact with the two sealing elements simultaneously. The differences between the two pistons are only the areas that ensure the sealing elements enlargement.

\section{Testing Set-Up}

To evaluate the necessary closing force, an electromechanical universal testing machine, Instron 3369 Dual Column Testing System, equipped with a $50 \mathrm{kN}$ load cell was used (Instron, Norwood, MA, USA). The evaluation of the necessary closing force was made for a stroke of $8 \mathrm{~mm}$, which corresponds to the insertion path stroke and a feed rate of $1 \mathrm{~mm} / \mathrm{s}$. In the real case, the insertion path is realized by releasing the compression springs of the closing mechanism. To properly dimension the compression springs of the closing mechanism, several tests are required to determine the most suitable geometry of the piston and to gather data regarding the closing force value considering different operational temperatures.

\section{Verification Philosophy}

Tests were conducted for both kinds of seals (Type I and Type II), for different configurations, such as:

- $\quad$ Device equipped with large seal;

- $\quad$ Device equipped with small seal;

- Device equipped with both seals. 
As initially stated, the tests should be performed at operational temperatures, $-40{ }^{\circ} \mathrm{C}$ and $80^{\circ} \mathrm{C}$. Following the ECSS-E-ST-33-01C standard [19], the test temperatures shall take into consideration $\mathrm{a} \pm 5{ }^{\circ} \mathrm{C}$ margin and also the worst-case scenario. Thus, by considering both the operational temperatures and ECSS standards, the tests were performed at $-20^{\circ} \mathrm{C}$ (as an intermediate temperature evaluation), at $-60^{\circ} \mathrm{C}$ (worst case scenario-the minimum operational temperature is $-45^{\circ} \mathrm{C}$ ), at $20{ }^{\circ} \mathrm{C}$ (environmental temperature) and $+70{ }^{\circ} \mathrm{C}$. Testing at $+85^{\circ} \mathrm{C}$ could not be performed due to a limitation of the test rig that could not maintain a stable elevated temperature. The temperature during the test was measured using a type T thermocouple (S.C. CAOM S.A, Pascani, Romania). As specified before, two piston shapes (conical and toroidal) were used for the force evaluation. The tests with only one seal (large or small) were performed to determine the behaviour for each independent seal, but for the compression spring dimensioning, the results obtained when the device was equipped with both seals were used. For each test, a test sequence was followed and conducted to ensure the traceability and repeatability of the test. The test is divided into several phases, as described in Table 3.

Table 3. Testing phases for sealing force evaluation.

\begin{tabular}{cl}
\hline Phase & \multicolumn{1}{c}{ Description } \\
\hline & $\begin{array}{l}\text { Device set-up on Instron tensile testing machine (an "empty test" was performed to } \\
\text { determine the friction force without the sealing elements). To be sure that there is no } \\
\text { friction force between the testing device metallic components, an "empty test" was } \\
\text { performed before and after the testing campaign. During the "empty test" the } \\
\text { testing device was not equipped with the sealing elements. }\end{array}$ \\
& $\begin{array}{l}\text { Installing and testing the large seal (L), dismounting the large seal and mounting the } \\
\text { small seal (S). }\end{array}$ \\
3 & $\begin{array}{l}\text { Install and test both sealing elements (large and small). } \\
\text { Perform an "empty test"-to see if the testing device suffers any deformation which } \\
\text { can lead to additional friction forces. }\end{array}$ \\
\hline
\end{tabular}

\section{Closing Force Measurement}

Before starting to evaluate the closing force, an empty test (without seals) was performed (as presented in Figure 13) to be sure that the contact/friction forces between the piston (sample container mock-up) and the cylinder (vault mock-up) are negligible. After the closing force evaluation tests were finished, another empty test was also performed.

\subsection{Piston-Conical Shape}

Following the initial empty tests, Type I and Type II seals were tested at the worst-case scenario $\left(-65^{\circ} \mathrm{C}\right)$, ambient temperature $\left(+20^{\circ} \mathrm{C}\right)$ and the highest possible temperature $\left(+70^{\circ} \mathrm{C}\right)$. Figure 14 illustrates the testing set-up for both extreme temperatures and the thermocouple positioning.

For each type of test/configuration, several determinations at 1-min intervals were made successively. The forces obtained decreased after each test because, when introducing the piston in the cylinder, the sealing elements are enlarged. After pulling out the piston, the sealing elements are free, but they do not come back immediately to the initial shape. Because of that, when performing the next closing, their enlargement is smaller and, thus, the necessary force is smaller. For the piston with conical shape (CO) tests were performed firstly and for each sealing element along with tests with both sealing elements mounted at the same time. In the following paragraphs, the term "new seal" will be used every time a sealing element is tested for the first time. Maximum obtained closing forces for each Type I and Type II seals at environment temperature $\left(+20^{\circ} \mathrm{C}\right)$ are marked in Figure 15. 


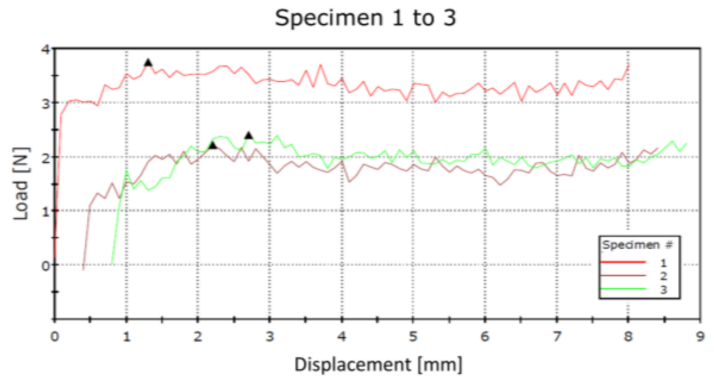

(a)

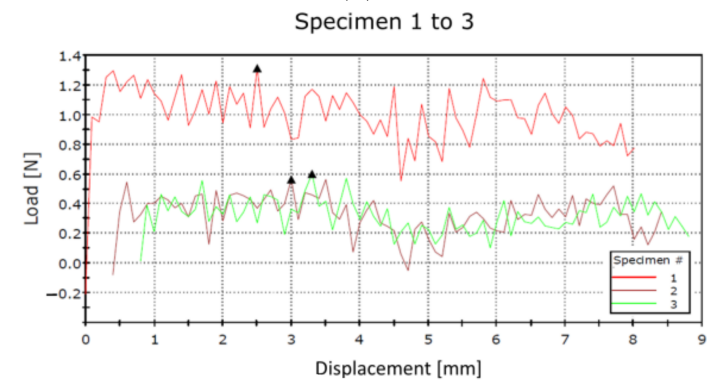

(b)

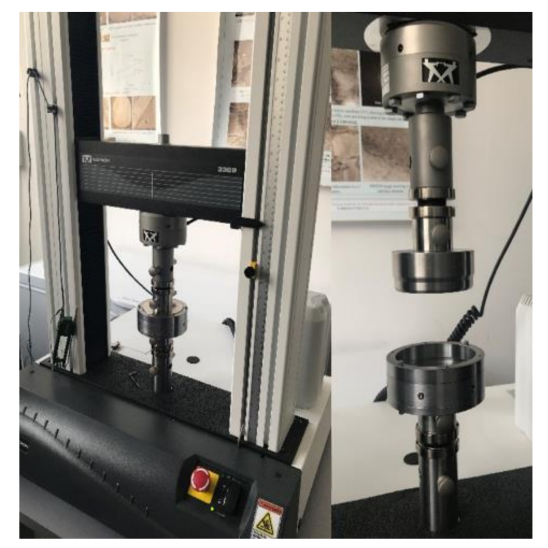

(c)

Figure 13. Empty tests results at: (a) the start of the testing campaign, (b) the end of the testing campaign) and (c) "empty test" set-up.

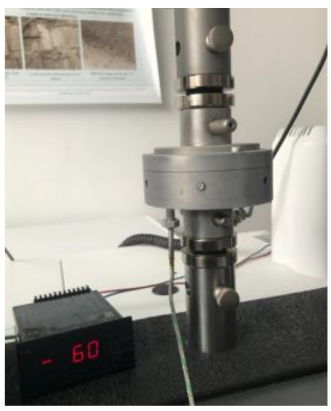

(a)

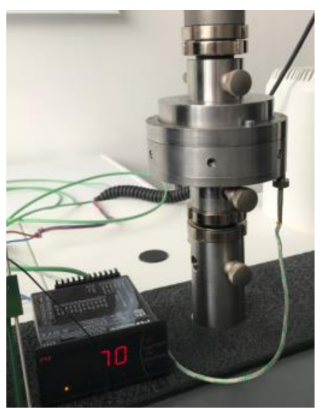

(b)

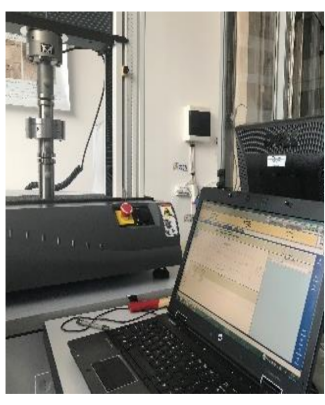

(c)

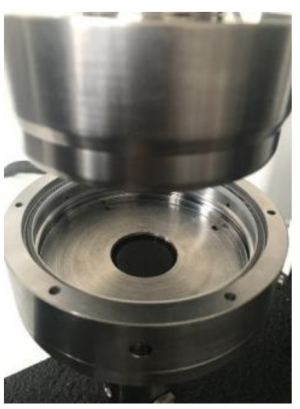

(d)

Figure 14. Closing force evaluation for (a) $-60{ }^{\circ} \mathrm{C}$ and (b) $+70{ }^{\circ} \mathrm{C}$ using a thermocouple and the (c) test set-up with (d) a detailed view of the testing device.

From the results presented in Figure 15, the maximum measured values for the friction force at environmental temperature were extracted, respectively $608 \mathrm{~N}$ for Type I seal and $379 \mathrm{~N}$ for Type II seal, as shown in Figure 16.

Considering the graph plotted in Figure 16, it can be seen that the Type I seals that were individually tested (closing force evaluation for one seal), have a different behaviour than the new seals. The maximum force for Type I-b new seals (CO) configuration is around $608 \mathrm{~N}$ and the maximum force for Type I-a (CO) (individually tested) configuration is around $470 \mathrm{~N}$. The Type II seals have almost the same behaviour and the maximum force is around $379 \mathrm{~N}$. The force curves do not have the same starting point, where Type I-b new seals (CO) start at $1.7 \mathrm{~mm}$, Type I-a (CO) start at $2.3 \mathrm{~mm}$ and Type II-a (CO) start at $3.1 \mathrm{~mm}$. This is because there are some gaps between the piston/vault mock-up and the testing machine gripping devices. This aspect can be observed for all the graphs which are presented in this paper, but these gaps do not affect the maximum closing force determination. 

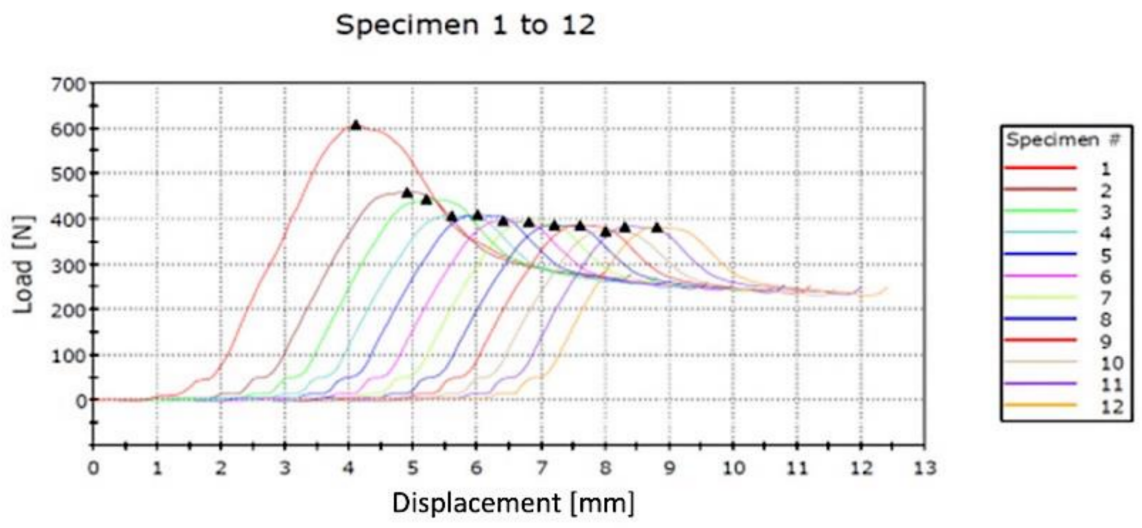

(a)

Specimen 1 to 12
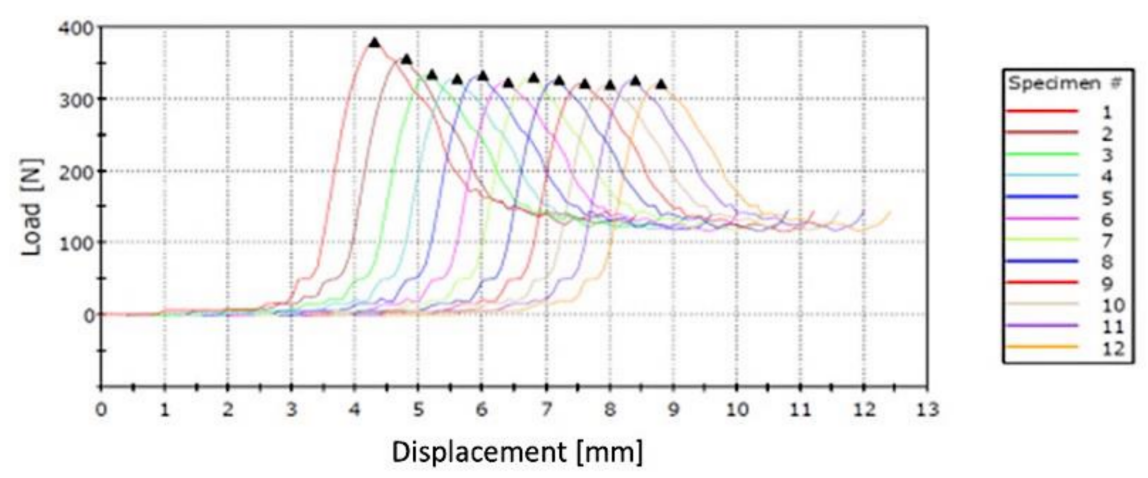

(b)

Figure 15. Closing force evaluation at environmental temperature for (a) Type I seal and (b) Type II seal (peak values highlighted by black triangles).

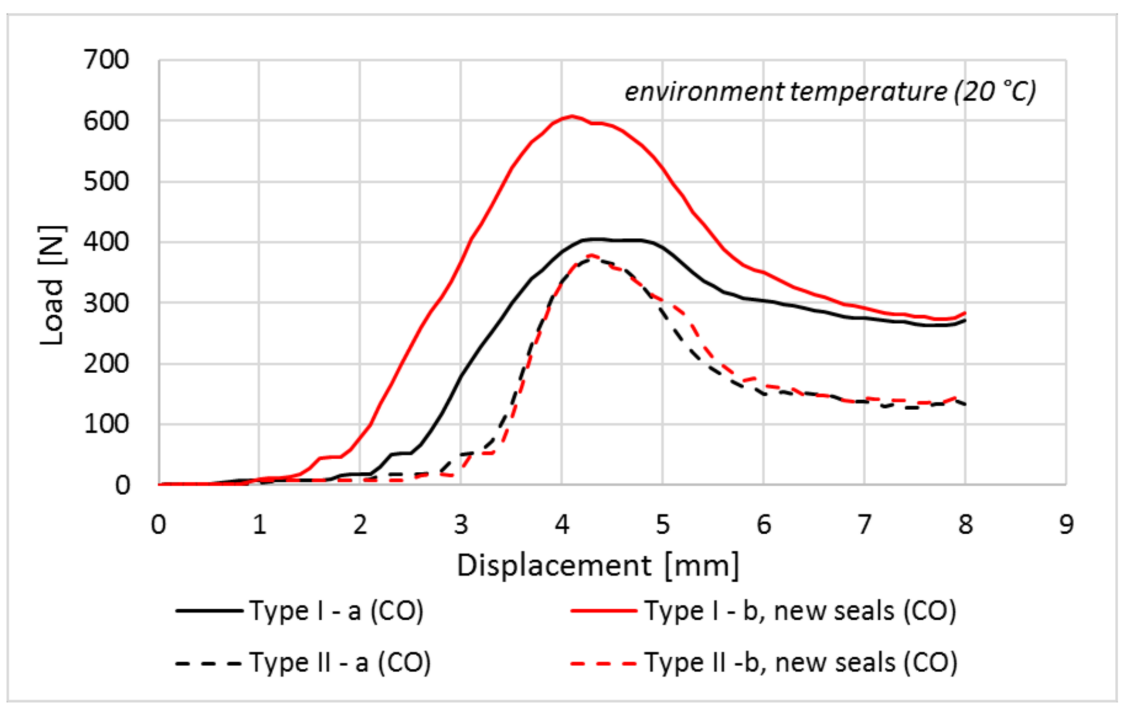

Figure 16. Closing force curves obtained at environmental temperature.

To analyse the temperature effect over the closing force, it was decided to perform a new test at $-20^{\circ} \mathrm{C}$. After this test, it was identified that the force for Type I seals was $1330 \mathrm{~N}$, while for Type II was $799 \mathrm{~N}$ (Figure 17). 


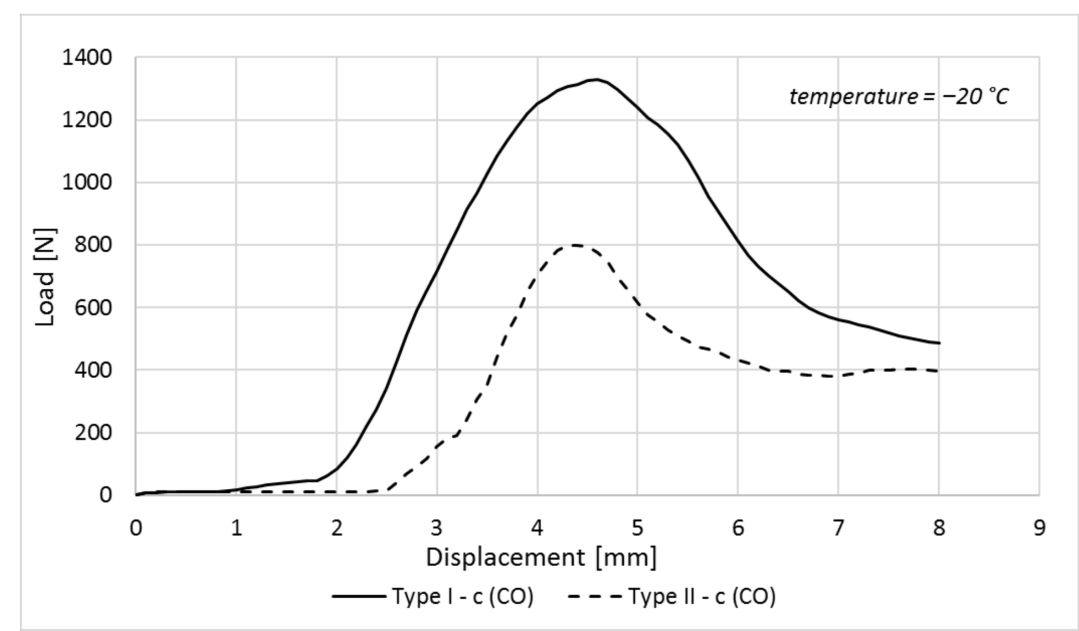

Figure 17. Closing force curves obtained for $-20^{\circ} \mathrm{C}$.

As expected, the closing force increased when the operating temperature dropped. Similar to the test performed at $+20^{\circ} \mathrm{C}$, the graphs tendency is kept, Type I seals requiring higher forces than Type II. From Figure 17, it can be observed that there is a difference of around $500 \mathrm{~N}$ between the maximum closing force for Type I seals and Type II seals.

For a better evaluation of the temperature effect over the closing force, it was decided to conduct a test at $-60{ }^{\circ} \mathrm{C}$, a temperature that is lower than the closing mechanism operational temperature $\left(-45^{\circ} \mathrm{C}\right)$. After the test was conducted at $-60^{\circ} \mathrm{C}$, a maximum force of $2266 \mathrm{~N}$ was determined for the Type I seal and $1419 \mathrm{~N}$ for the Type II seal, as can be seen from Figure 18.

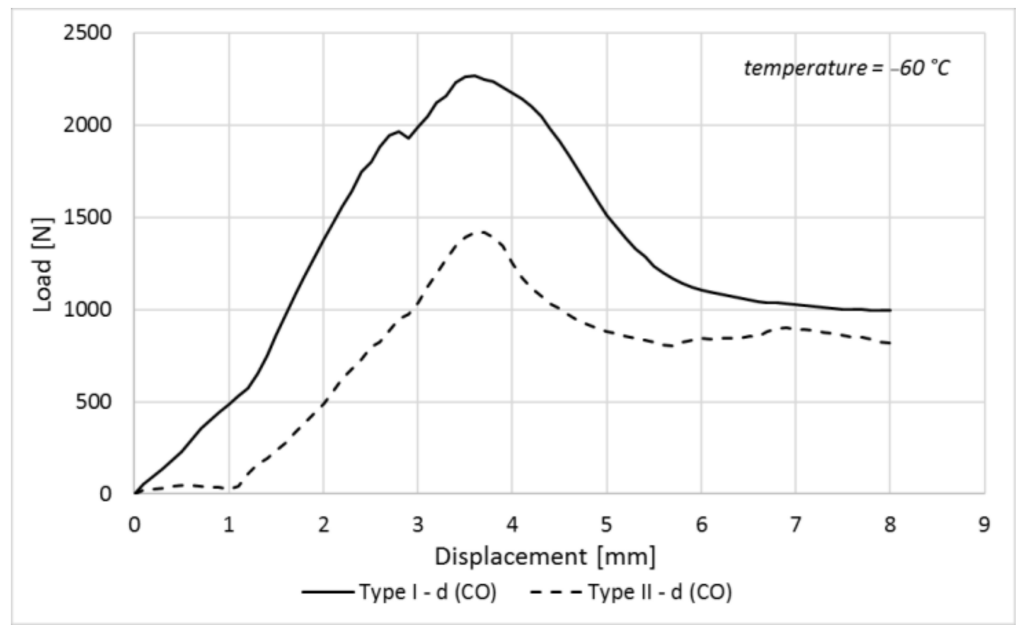

Figure 18. Closing force curves were obtained for $-60^{\circ} \mathrm{C}$.

The analysis of the results obtained for the closing test performed at $-60^{\circ} \mathrm{C}$ reveals that the tendency between the two closing force curves is kept and the difference between the peaks of the two forces is around $850 \mathrm{~N}$.

Considering all the results obtained for the piston with a conical shape, an interpolation was performed. Figure 19 presents the closing force/temperature dependency for Type I and Type II seals. One can observe that the differences between the two types of sealing elements are kept on all the temperature domains, and the results obtained for this type of piston have a large influence over the closing and sealing mechanism final design. For a better overview, the test results (load vs. displacement) for all temperature cases are plotted in Figure 20. 


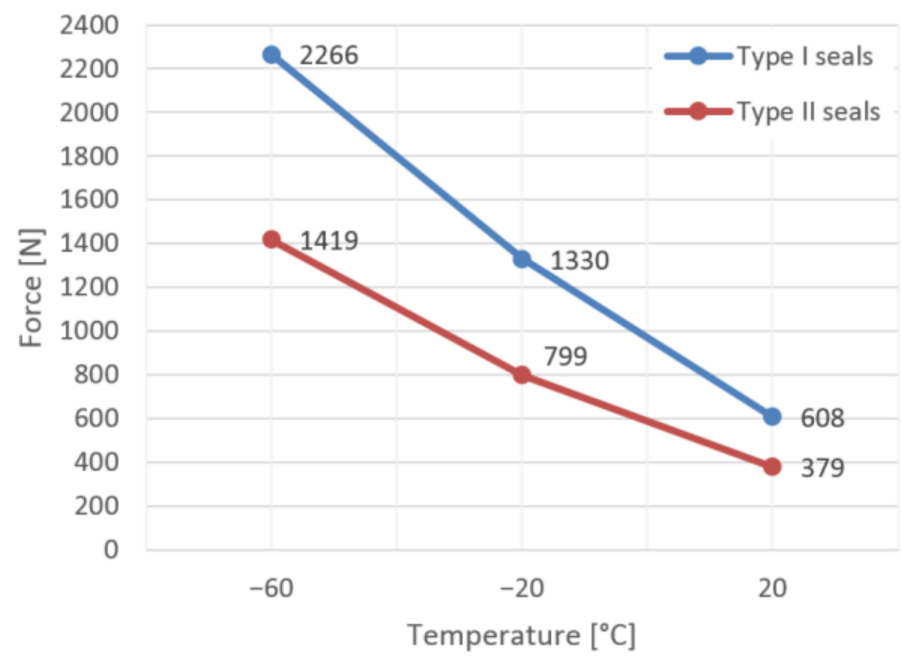

Figure 19. Closing force vs. temperature dependency for Type I and Type II seals-piston with a conical shape.

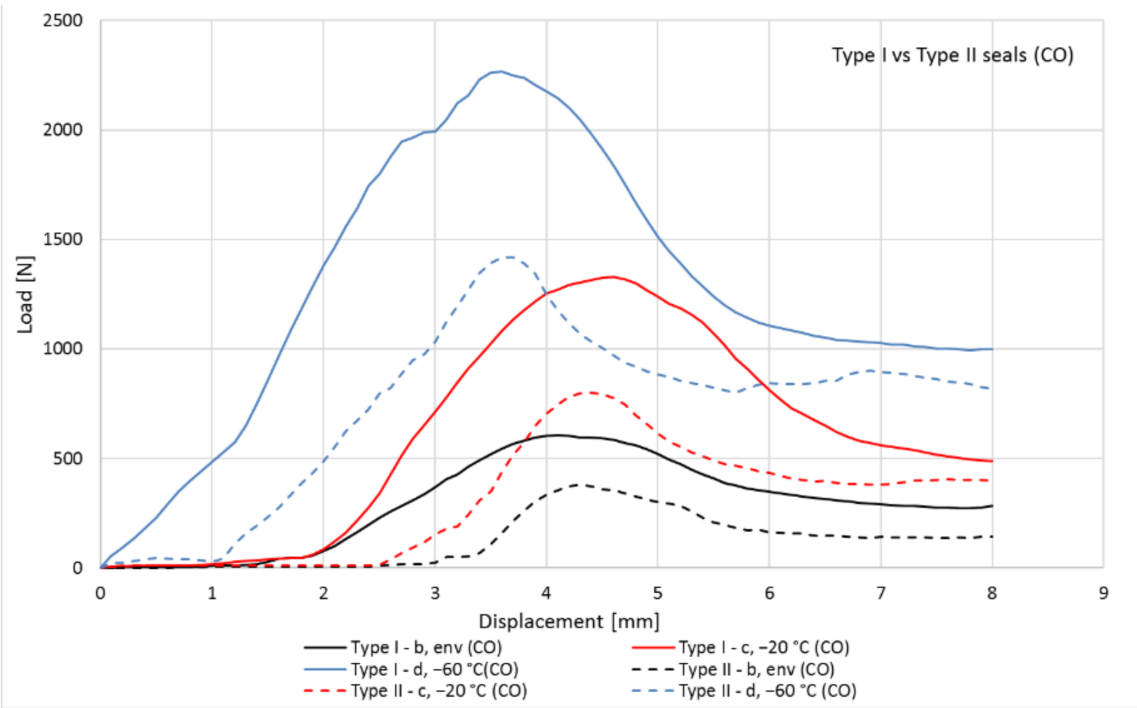

Figure 20. Type I and Type II seals closing forces for the piston with a conical shape.

The obtained results are considerably higher than the ones provided by the theoretical analysis (performed based on sealing elements specifications) and the force which shall be overcome by the mechanical press cannot be ensured only by three compression springs. From this analysis, it was concluded that the maximum pushing force of the piston occurs when the piston starts to enlarge the sealing elements. For decreasing the value of this force, a piston with a new geometrical shape (toroidal shape) was designed and manufactured.

\subsection{Piston-Toroidal Shape and Comparison Evaluation of Their Impact over the Mechanism Design}

To be able to perform a comparative analysis between the two piston geometries, a test was firstly conducted for the toroidal piston at environmental temperature and the results are presented in Figure 21. Following the toroidal piston test, a first comparison regarding the necessary force for the closing operation was made using the results obtained for the two pistons (conical and toroidal shape) at ambient temperature and presented in Figure 22. 


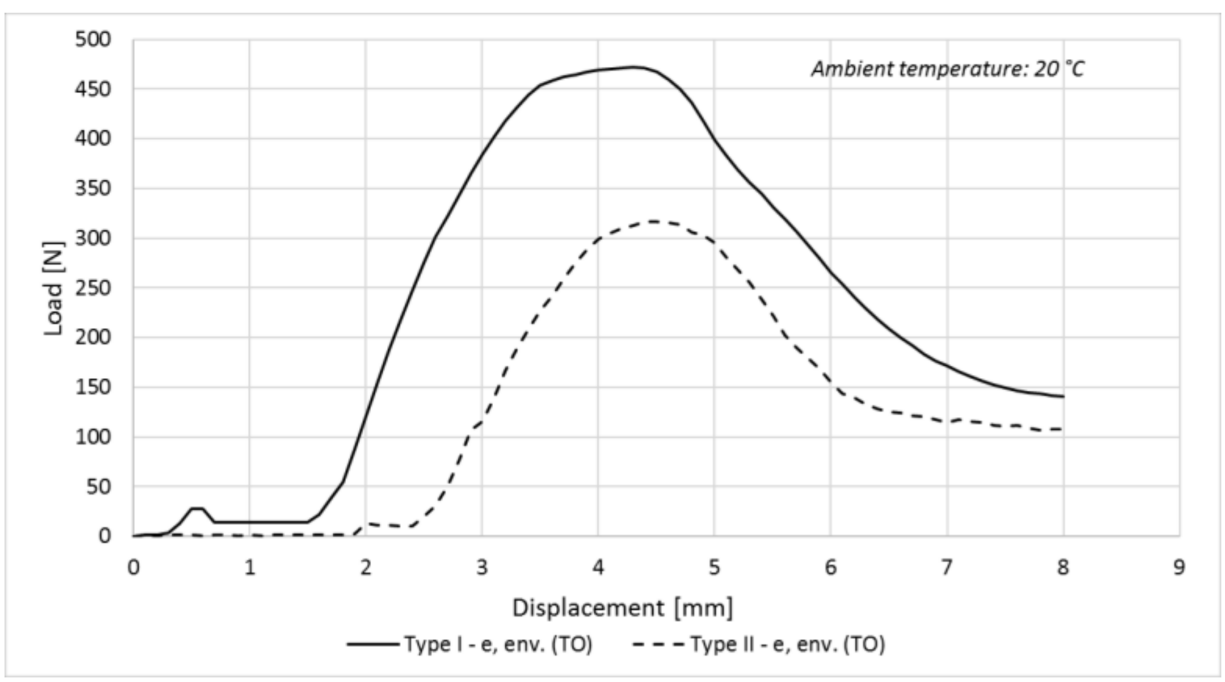

Figure 21. Closing force curves obtained at environmental temperature-piston with toroidal shape.

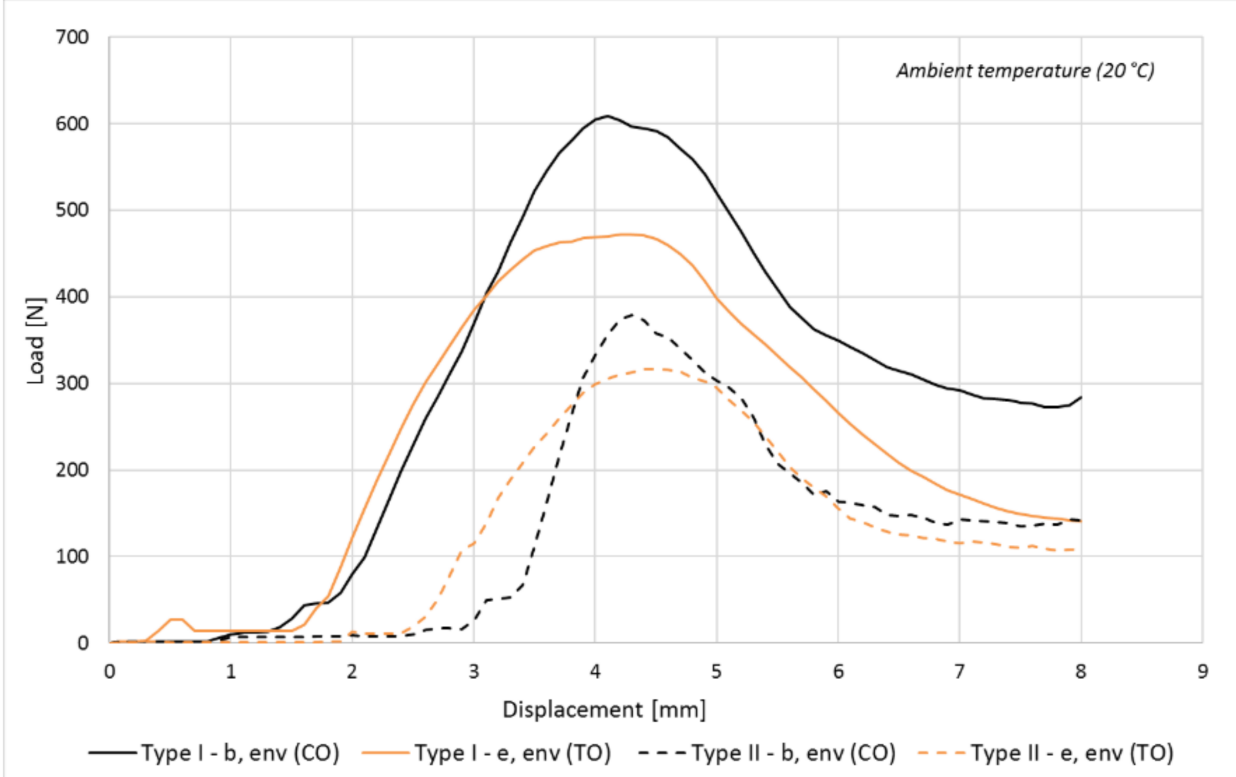

Figure 22. Type I seals vs. Type II seals closing force for conical shape vs. toroidal shape pistons.

The results show that the closing force is lower using the piston with a toroidal shape for both types of sealing elements. Thus, a decision was made to analyse in detail the closing force values for the piston with toroidal shape along with their influence over the design of the sealing and closing system.

For the piston with a toroidal shape (TO), the same testing sequence was followed with regard to the temperature, types of sealing elements and testing procedure.

Based on the partial results, it was concluded that the worst-case scenario (the highest values for the closing force) corresponds to the tests performed at $-60{ }^{\circ} \mathrm{C}$. Thus, taking into account the temperature influences, several closings and closing force evaluation tests were performed at a temperature of $-60^{\circ} \mathrm{C}$, but also at a positive temperature $\left(+70{ }^{\circ} \mathrm{C}\right)$. In Figure 23 the maximum force/displacement curves are presented for both sealing elements (Type I and Type II), at different operating temperatures and in Table 4 are summarized the results from the previous tests using the piston with a toroidal shape. 


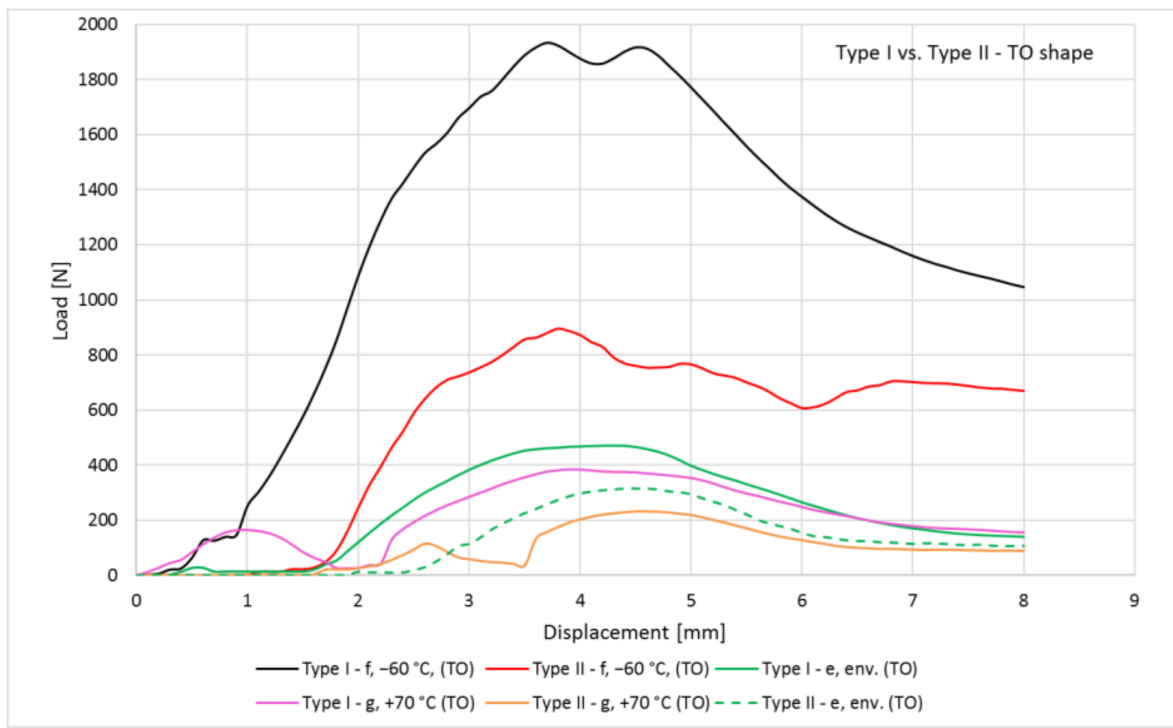

Figure 23. Type I and Type II seals closing forces for the piston with toroidal shape-displacement vs. load.

Table 4. Closing force evaluation results were obtained for the piston with a toroidal shape.

\begin{tabular}{ccc}
\hline Type of Test & Type I Seal [N] & Type II Seal [N] \\
\hline$+20^{\circ} \mathrm{C}$ & 471 & 317 \\
$-60^{\circ} \mathrm{C}$ & 1932 & 897 \\
$-60^{\circ} \mathrm{C}$ & 1915 & 997 \\
$-60^{\circ} \mathrm{C}$ & 2265 & 896 \\
$+70^{\circ} \mathrm{C}$ & 384 & 232 \\
\hline
\end{tabular}

The previous tests performed with the piston having a toroidal shape at $-60{ }^{\circ} \mathrm{C}$ lead to the decision of increasing the test number for Type II seals to have a better understanding of their behaviour. Maximum obtained forces for each Type II seal test at $-60{ }^{\circ} \mathrm{C}$ are marked in Figure 24.

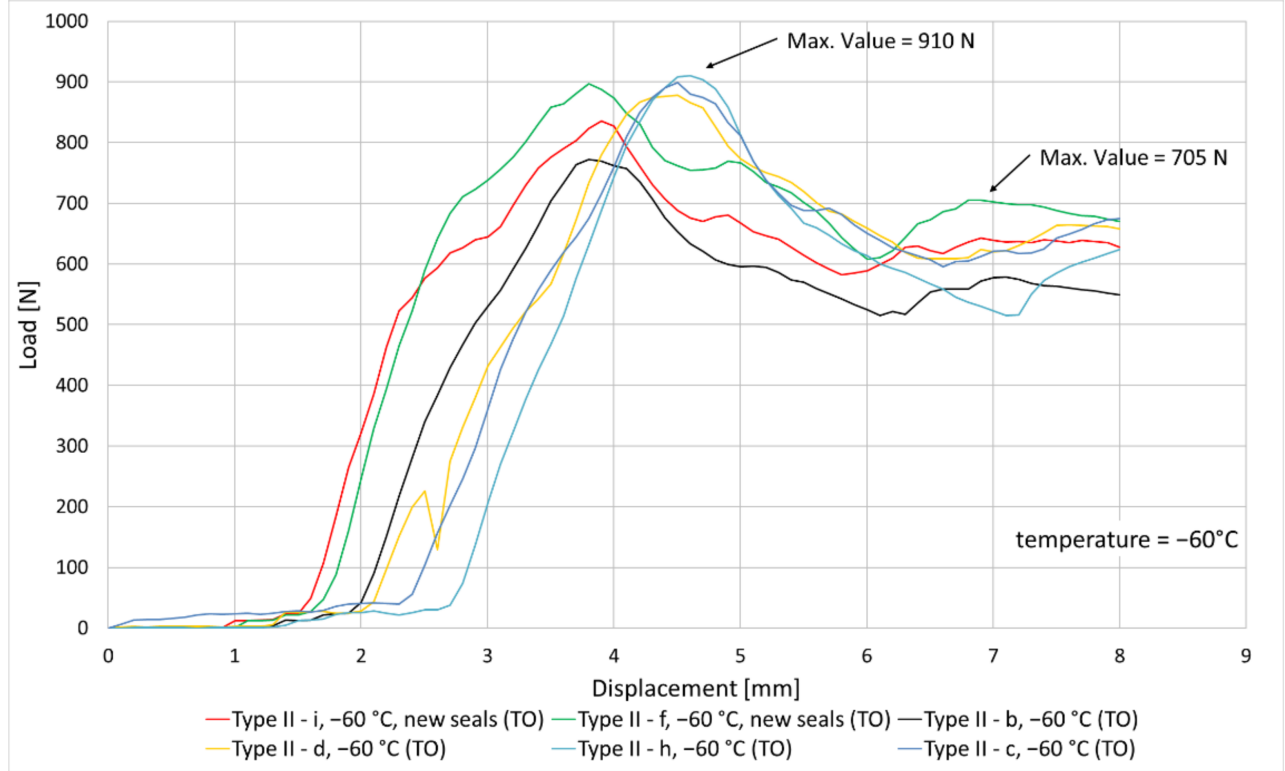

Figure 24. Closing force curves were obtained for Type II seals at $-60{ }^{\circ} \mathrm{C}$ with toroidal shaped lid. 
Based on all the tests performed with the piston with toroidal shape, the closing force as a function of temperature dependence is plotted in Figure 25 for each scenario. It can be observed that the negative temperature has a significant influence over the closing force and that the force value on the cylindrical area remains approximately constant for both types of seals. As in the previous case, the highest values of the closing force for each type of sealing element were considered and interpolated.

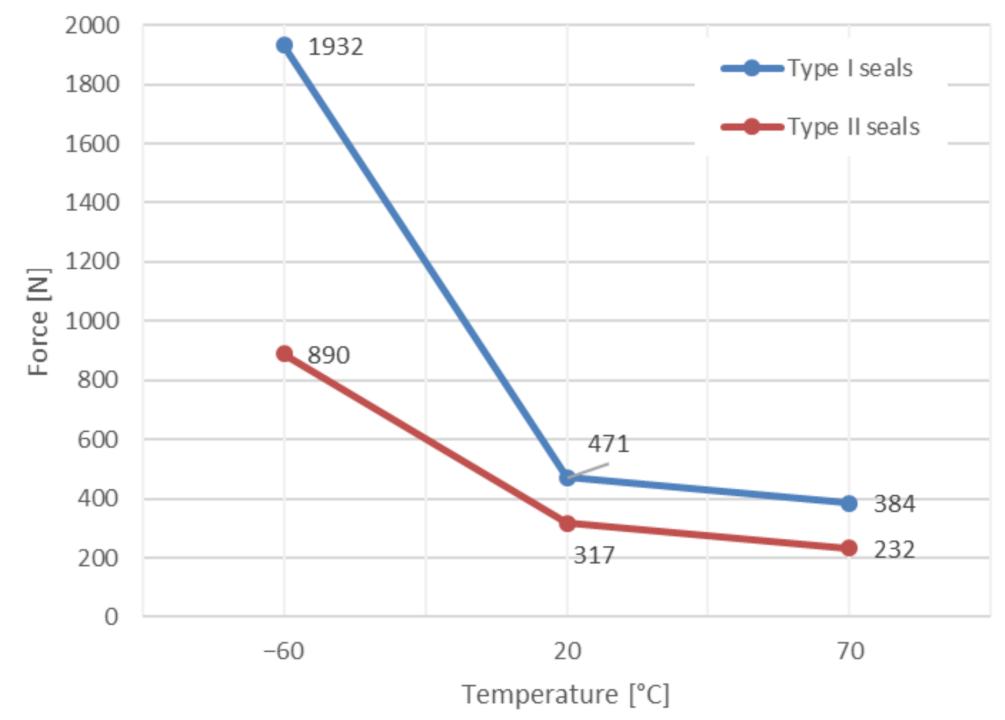

Figure 25. Type I and Type II seals closing forces for the piston with toroidal shape as a function of the temperature.

Summarizing all the data previously presented, it was determined that the toroidal shape piston along with Type II seals ensure the lowest closing force, leading to the decision of considering these aspects later in the mechanical press design.

\subsection{Mechanical Press Motorization}

Using the worst-case scenario for Type II seals with toroidal shape for the piston (Figure 24) and taking into account the ECSS-E-ST-33-01C standard [19], the next development step consisted in performing the mechanical press motorization. The actuation force necessary to close the vault is supplied by the Mechanical Press which shall be equipped with several helical compression springs defined after the motorization calculus. For the mechanical press motorization calculus, it was considered the worst-case scenario of the closing force operation which is the one performed at minimum operational temperature $\left(-40^{\circ} \mathrm{C}\right)$.

In Figure 26 the measured values of the closing force are shown and they were obtained following the testing campaign $\left(-60^{\circ} \mathrm{C}\right.$, environmental temperature and $\left.+70{ }^{\circ} \mathrm{C}\right)$ for the toroidal shape piston and using Type II seals.

Interpolating the results of the test obtained at $-40{ }^{\circ} \mathrm{C}$, two force values were determined, at $3 \mathrm{~mm}$ displacement $(\mathrm{Fs} 1=748 \mathrm{~N}$ ), respectively $8 \mathrm{~mm}$ displacement (end of the stroke, Fs2 = $552 \mathrm{~N}$ ). Considering the specifications mentioned in the ECSS-E-ST-33-01C standard [19] for motorization and actuation factors (sections 4.7.5.3.1e and 4.7.5.3.2e), the minimum actuation forces which shall be ensured by the MP were obtained. The results regarding the minimum actuation forces are summarized in Table 5. 


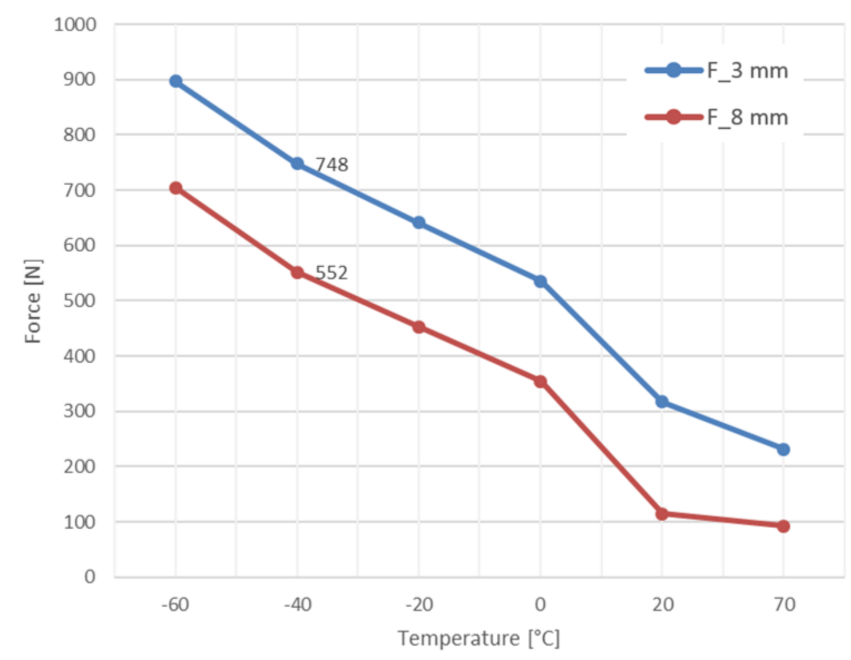

Figure 26. Measured reference values.

Table 5. Mechanical press motorization calculus considering forces at $-40{ }^{\circ} \mathrm{C}$.

\begin{tabular}{cccc}
\hline Displacement [mm] & $\begin{array}{c}\text { Closing Force Obtained } \\
\text { from Test [N] }\end{array}$ & $\begin{array}{c}\text { Closing Force Considering } \\
\text { ECSS-E-ST-33-01C Specifications [N] }\end{array}$ & Observations \\
\hline 3 & Fs $1=748$ & $\mathrm{~F} 1=0.8 \times 3 \times \mathrm{Fs} 1=1795.2$ & Motorization factor: \\
$2 \times 1.5=3$ & Actuation factor: 0.8 \\
\hline
\end{tabular}

Where, Fs1, Fs2-closing forces obtained from tests; 0.8-actuation factor; 3-motorization factor.

The driving force applied by the MP springs will linearly decrease from the initial value to a final value at the end of the closing stroke. The driving force values must be above the reference values F1 and F2 set above. Based on the obtained F1 and F2 forces (Table 5), the helical compression springs of the MP were dimensioned. Considering this, the MP dimensioning was made, respectively how the spring force varies during the $8 \mathrm{~mm}$ stroke, which must be ensured by the closing mechanism so that the vault will be in a closed position. The force delivered by the MP during the closing stroke is given in Figure 27 and it can be observed that the driving force curve is above the reference value set according to the testing campaign results and ECSS standards guideline.

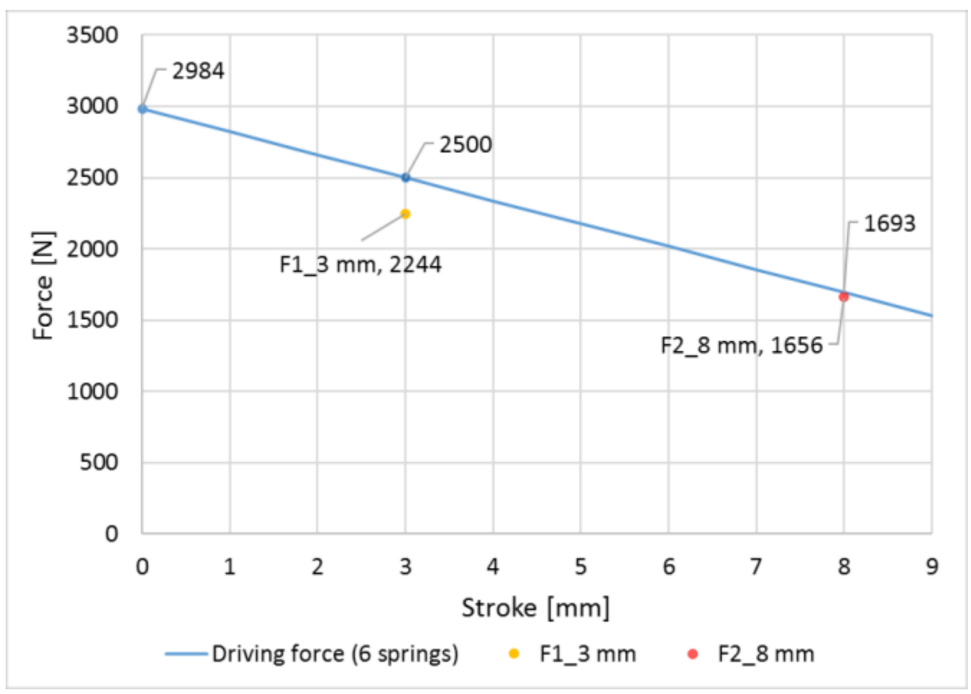

Figure 27. Mechanical Press delivered force during the Vault's closing. 
Taking into consideration all this information, the mechanical press was designed and presented in Figure 28, with 6 compression springs (spring codification 76/1/3, Hennlich supplier) for the following reasons:

- The available space for mounting the compression springs is small;

- To achieve a uniform distribution of the force on the vault circumference;

- The requirement to obtain a high closing force (according to the test results presented above);

- The necessity to ensure an $8 \mathrm{~mm}$ stroke to perform the vault closing operation.

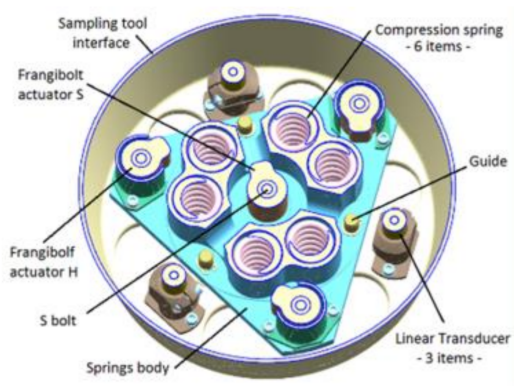

\begin{tabular}{|l|c|l|}
\hline Spring number & \multicolumn{2}{|c|}{$76 / 1 / 3$ (HENNLICH supplier) } \\
\hline \multicolumn{3}{|c|}{ Characteristics } \\
\hline Material & 1.4310 stainless steel & \\
\hline Wire diameter & 3.2 & $\mathrm{~mm}$ \\
\hline Outside diameter & 19.2 & $\mathrm{~mm}$ \\
\hline Solid height (Lsolid) & 36.9 & $\mathrm{~mm}$ \\
\hline Nominal free length (Lo) & 59 & $\mathrm{~mm}$ \\
\hline Spring rate (R) & 26.88 & $\mathrm{~N} / \mathrm{mm}$ \\
\hline & \\
& \\
& \\
\end{tabular}

Figure 28. Mechanical press design and spring characteristics.

\section{Conclusions}

During the testing campaign, two types of sealing elements and two shapes of the sealing surfaces for the Sample Container were investigated to obtain smaller forces during the closing operation. The seals with a U-shaped spring and jacket made of Fluoroloy A28 (Type II seal) require a smaller force than the other one (Type I seal). It was concluded that the toroidal shape piston needs a smaller force to enlarge the jacket and spring of the sealing elements.

The sealing elements are composed of a plastic jacket and a metallic spring. The flexibility of the jacket material is temperature-dependent, stiffer at lower temperatures and softer at higher temperatures. Due to this behaviour, the testing campaign was performed considering different temperatures (environmental temperature $\left(20^{\circ} \mathrm{C}\right),-20^{\circ} \mathrm{C},-60^{\circ} \mathrm{C}$ and $+70^{\circ} \mathrm{C}$ ) which confirmed that the closing force is temperature-dependent too. Using the results from the testing campaign, especially the ones at $-60^{\circ} \mathrm{C}$, which represent the worst-case scenario, the maximum closing force which shall be ensured by the mechanical press was identified. The testing campaign is vailable at the Supplementary Materials.

The obtained results from the testing campaign were used as input for the mechanical press motorization, which consists in dimensioning the helical compression springs foreseen to deliver the closing force. More exactly, based on these tests and calculations, the necessary spring rate to develop a sufficiently large force to ensure the vault closing was established. During the testing campaign of the closing and sealing system, the mechanical press design was validated through functional closing tests.

As each Space Agency (i.e., ESA, NASA, JAXA) is focused on exploring planet Mars or Martian Moons and collecting regolith samples from Mars natural satellites in future missions, the work carried out in the design, manufacturing and testing a sealing and closing mechanism for a Phobos Sample Return Mission was highly appreciated by ESA. This represents a high possibility that the system architecture designed by COMOTI to be used in future scheduled missions. It should also be highlighted that the possibility of the mechanism to be scaled up and used in Sample Return Missions will need a higher closing force or be able to cope with higher robotic arm misalignments. 
Supplementary Materials: Testing campaign https:/ / youtu.be/dVGQD0cqMDk?list=LL, Video S1: Sealing and Closing System-Breadboard Testing Campaign (accessed on 4 May 2020).

Author Contributions: Conceptualization, G.M.; methodology, R.M., G.M., D.M. and A.P.; software, R.M., D.M. and I.F.P.; validation, R.M., G.M., D.M. and I.F.P.; formal analysis, R.M., G.M. and D.M.; investigation, R.M., G.M. and D.M.; resources, R.M., D.M., I.S.V. and A.P., data curation, R.M., G.M., D.M. and I.F.P.; writing — original draft preparation, R.M., D.M., I.F.P. and I.S.V.; writing-review and editing, I.F.P. and I.S.V.; visualization, I.F.P. and I.S.V.; supervision, R.M.; project administration, R.M.; funding acquisition, R.M. All authors have read and agreed to the published version of the manuscript.

Funding: This work was performed in the frame of Breadboard of Sealing and Closing System for a Phobos Sample Return Mission, contract number 4000115017/15/NL/PA, funded by the European Space Agency (ESA). The APC was funded by the "NUCLEU" Program TURBO 2020+, Grant no. 2N/2019, supported by the Romanian Minister of Research, Innovation and Digitalization.

Institutional Review Board Statement: Not applicable.

Informed Consent Statement: Not applicable.

Data Availability Statement: Not applicable.

Acknowledgments: The authors would like to thank you for their continuous support and guidance to the members of the Structures and Mechanisms Department from ESTEC (ESA) and Emanuele Piersanti from Officina Stellare. The authors wish to thank Trelleborg Sealing Solutions Bulgaria and Saint-Gobain Belgium for providing the custom-made sealing elements used and presented in this paper.

Conflicts of Interest: The authors declare no conflict of interest. The funders had no role in the design of the study; in the collection, analyses, or interpretation of data; in the writing of the manuscript, or in the decision to publish the results.

\section{References}

1. European Space Agency. Mars Robotic Exploration Preparation-2 Programme, Technology Plan. Available online: https://sci. esa.int/documents/34490/36224/1567260272583-MREP2_Technology_Plan_Public_20151218.pdf (accessed on 19 August 2021).

2. Ramsley, K.R.; Head, J.W. Mars impact ejecta in the regolith of Phobos: Bulk concentration and distribution. Planet. Space Sci. 2013, 87, 115-129. [CrossRef]

3. Huntress, W.T.; Marov, M.Y. Soviet Robots in the Solar System: Mission Technologies and Discoveries; Springer: New York, NY, USA, 2011; ISBN 978-1-4419-7898-1. [CrossRef]

4. Siddiqi, A.A. Beyond Earth-A Chronicle of Deep Space Exploration, 1958-2016; NASA SP-2018-4041; National Aeronautics and Space Administration, NASA History Division: Washington, DC, USA, 2018.

5. Zelenyi, L.M.; Zakharov, A.; Polischuk, G.M.; Martynov, M.B. Project of the mission to Phobos. Sol. Syst. Res. 2010, 44, 15-25. [CrossRef]

6. European Space Agency. Phobos Sample Return—CDF Study Report, CDF-145(C); ESA-ESTEC Concurrent Design Facility: Noordwijk, The Netherlands, 2014.

7. European Space Agency. Mars Sample Return Overview Infographic. 27 May 2019. Available online: https://www.esa.int/ESA_ Multimedia/Images/2019/05/Mars_Sample_Return_overview_infographic (accessed on 5 July 2021).

8. Miyamoto, H. Japanese Mission of the two Moons of Mars with Sample Return from Phobos; Mars Exploration Program Analysis Group, Jet Propulsion Laboratory, California Institute of Technology, University of Tokyo: Tokyo, Japan, 3 March 2016.

9. Japanese Aerospace Exploration Agency, MMX-Martian Moons Exploration. Available online: https://www.mmx.jaxa.jp/en/ (accessed on 5 July 2021).

10. National Aeronautics and Space Administration. MARS Exploration Program. Available online: https://mars.nasa.gov/ (accessed on 5 July 2021).

11. National Aeronautics and Space Administration. MARS Exploration Program, Concepts for Mars Sample Return. Available online: https: / / mars.nasa.gov/mars-exploration/missions/mars-sample-return/ (accessed on 5 July 2021).

12. Wall, M. Pieces of Heaven: A Brief History of Sample-Return Missions, 8 September 2016. Available online: https://www.space. com/34002-sample-return-space-missions-history.html (accessed on 30 June 2021).

13. Chan, Q.H.S.; Stroud, R.; Martins, Z.; Yabuta, H. Concerns of Organic Contamination for Sample Return Space Missions. Space Sci. Rev. 2020, 216, 56. [CrossRef]

14. National Aeronautics and Space Administration. JPL Small-Body Database Browser: 25143 Itokawa (1998 SF3). Available online: https:/ / ssd.jpl.nasa.gov/sbdb.cgi?sstr=2025143 (accessed on 5 July 2021). 
15. National Aeronautics and Space Administration. JPL Small-Body Database Browser: 162173 Ryugu (1999 JU3). Available online: https:/ / ssd.jpl.nasa.gov/ sbdb.cgi?sstr=2162173 (accessed on 5 July 2021).

16. National Aeronautics and Space Administration. OSIRIS-REx Mission Overview. Available online: https://solarsystem.nasa. gov/missions/osiris-rex/in-depth/ (accessed on 30 June 2021).

17. Okazaki, R.; Sawada, H.; Yamanouchi, S.; Tachibana, S.; Miura, Y.N.; Sakamoto, K.; Takano, Y.; Abe, M.; Itoh, S.; Yamada, K.; et al. Hayabusa2 Sample Catcher and Container: Metal-Seal System for Vacuum Encapsulation of Returned Samples with Volatiles and Organic Compounds Recovered from C-Type Asteroid Ryugu. Space Sci. Rev. 2017, 208, 107-124. [CrossRef]

18. Sawada, H.; Okazaki, R.; Tachibana, S.; Sakamoto, K.; Takano, Y.; Okamoto, C.; Yano, H.; Miura, Y.; Abe, M.; Hasegawa, S.; et al. Hayabusa 2 Sampler: Collection of Asteroidal Surface Material. Space Sci. Rev. 2017, 208, 81-106. [CrossRef]

19. European Space Agency. European Cooperation for Space Standardization, ECSS-E-ST-33-01C Rev. 2, Space EngineeringMechanisms. 1 May 2019. Available online: https:/ / ecss.nl/ (accessed on 5 July 2021).

20. Mihalache, R.; Mihai, D.; Megherelu, G.; Popa, I.F.; Olaru, D.; Ifrim, D. Sealing Technologies Trade-Off for a Phobos Sample Return Mission. Transp. Res. Procedia 2018, 29, 244-254. [CrossRef]

21. Flitney, R. Seals and Sealing Handbook; Butterworth-Heinemann: Burlington, MA, USA, 2014; ISBN 978-0-08-099416-1. [CrossRef] 